\title{
Comunicação, Resistência e Não Violência: as narrativas históricas da Rádio Comunitária Camponesa "Palmares""
}

\section{Communication, Resistance and No-violence: The historical narratives of Palmares Peasant Community Radio}

\author{
Jax Nildo Aragão Pinto ${ }^{1}$, Ingrid Gomes Bassi ${ }^{1}$
}

\begin{abstract}
Resumo: O presente artigo desenvolve a análise da narrativa histórica da Rádio Comunitária Camponesa "Palmares FM 106,3" do assentamento do Movimento dos Trabalhadores SemTerra (MST) em Parauapebas, região sudeste do Pará. Para isso, utilizamos a matriz metodológica qualitativa, de base colaborativa e não extrativista, a partir do corpus de análise de fevereiro de 2019. Como resultados e discussões, compreendemos as associações de resistência cultural e política da Rádio Palmares com as fundamentações sobre a importância da comunicação dialógica nas concepções de Freire (1971) e do uso da não violência, com base nas teorias de Muller (2007). Nas considerações finais, problematizamos a discussão do potencial dialógico ativo e de resistência não violenta da história da Rádio Comunitária e de sua importância para o movimento social camponês, numa região pulsante de diversidade e de interesses divergentes.
\end{abstract}

Palavras-Chave: Comunicação; Resistência; Não Violência; Narrativa Histórica; Rádio Palmares.

\begin{abstract}
This article analyses the historical narrative of the Peasant Community Radio "Palmares FM 106,3" of the landless workers movement (MST) in the city of Parauapebas, located in the southeast region of the state of Pará. For this we use the qualitative methodological matrix, based on collaborative and non-extractive basis, from the corpus of analysis of February 2019. As a result we understand the relations between the cultural and political resistence represented by Radio Palmares and Freire's (1971) conceptualization of the importance of dialogic communication and Muller's (2007) theories of the use of non-violence. In our conclusion we discuss the radio's potential of active, non-violent resistence as well as its dialogical character in the history of the Community Radio and its importance for peasant's social movement in a region thriving with diversity, diverging interests that favor violence and conflict.
\end{abstract}

Keywords: Communication; Resistence; No-violence; Historical Narrative; Radio Palmares.

\section{Introdução}

\subsection{Contexto do MST e região}

O Movimento dos Trabalhadores Rurais Sem-Terra (MST), desde a sua gênese, teve a comunicação como área estratégica de luta e resistência frente a opressões, violência e conflitos, decorrentes de suas atividades de ocupação de terras devolutas e latifúndios improdutivos no Brasil. No entanto, a comunicação do MST não se limita apenas ao uso dos meios disponíveis e à difusão de conteúdos que dão visibilidade à luta social no campo e à Reforma Agrária. O Movimento desenvolveu uma crítica aos

\footnotetext{
*Revisor: Pedro Henrique Tenório

${ }^{1}$ Universidade Federal do Sul e Sudeste do Pará
} 
meios de comunicação tradicionais e criou os seus próprios instrumentos de comunicação, como o Jornal do MST; Boletins e Tabloides locais, regionais e estaduais; Rádios e TVs Comunitárias/Alternativas em diversos assentamentos pelo país. Essas ações na área da comunicação exigiram investimentos na formação e qualificação de camponeses para atuar, seja no diálogo com os meios, seja no gerenciamento e produção nos veículos vinculados ao Movimento.

A estratégia comunicacional esteve historicamente ligada às dimensões cultural e educativa, passando por atualizações para dar respostas à metamorfose do Movimento e aos desafios da luta e resistência no campo brasileiro. Desta forma, Barbosa (2013) destaca quatro momentos importantes e frentes de atuação na área da comunicação: a) o uso do jornal como organizador coletivo; b) o jornal como meio de comunicação para auxiliar na construção da identidade nacional do Movimento; c) a construção de diferentes canais de comunicação para a base e para sociedade; d) a comunicação em interface com a educação, tornando-se elemento para a formação de militantes como estratégia para solução dos novos desafios enfrentados pelo Movimento.

O presente trabalho tem o objetivo de demonstrar a importância da Rádio Comunitária Palmares no processo de luta e resistência pela posse da terra no Sudeste Paraense, como um dos elementos centrais de alteração nas condições de vida dos camponeses na Amazônia. Trata-se de um estudo no assentamento Palmares II, com o objetivo de ressaltar a relevância da Rádio Comunitária, cujo lema é: uma onda de liberdade no ar, e que é destacada pelo Movimento como elemento imprescindível na estratégia de construção da Reforma Agrária e na difusão do modo de vida dos assentados, por vezes invisibilizada no contexto histórico das lutas sociais camponesas. A questão central que permeia o artigo é: em que medida a comunicação popular e dialógica produz e articula associações de resistência cultural e política nas narrativas e conteúdo da Rádio Palmares, fomentando a participação e a formação dos camponeses que atuam como protagonistas e sujeitos do processo de comunicação?

Peruzzo (2007, p. 3) enfatiza que os meios de comunicação comunitária são estratégicos para as organizações populares, tanto no processo de organização, como no de luta e resistência. Entre as principais características desse processo comunicacional, conforme destaca a autora, estão:

\footnotetext{
[...] a opção política de colocar os meios de comunicação a serviço dos interesses populares;

[...] transmissão de conteúdos a partir de novas fontes de informações (do cidadão comum e de suas organizações comunitárias);

[...] a comunicação é mais que meios e mensagens, pois se realiza como parte de uma dinâmica de organização e mobilização social;

[...] está imbuído de uma proposta de transformação social e, ao mesmo tempo, de construção de uma sociedade mais justa;

[...] abre a possibilidade para a participação ativa do cidadão comum como protagonista do processo (PERUZZO, 2007, p. 3).
}

A história da Rádio Comunitária Palmares - FM 106,3 -, localizada no Assentamento Palmares II, em Parauapebas, coloca-se nessa perspectiva teóricoconceitual, cuja práxis foi essencial para a consecução dos objetivos do MST no processo de organização e conquista da terra. A percepção de que a comunicação pressupõe encontro de consciências, de sujeitos históricos autônomos, de diálogo e partilha da vida social, supera qualquer possibilidade de limitá-la apenas a meios ou mensagem (FREIRE, 1971). 
Portanto, o desenvolvimento da comunicação como espaço de interação do mundo da vida (HABERMAS, 1984) se coloca como ferramenta da não violência, construindo territórios de colaboração, cuidado e cooperação no meio rural amazônico, muitas vezes marcado pelo estigma da colonialidade ${ }^{1}$ do poder e do saber, conflitualidade e violência.

\subsection{Aspectos históricos}

O Assentamento Palmares II é um dos símbolos da luta e resistência pela terra no Pará, região amazônica. Ao longo de seus 25 anos de história se coloca no contexto de espacialização do MST no Pará, em fins dos anos 80 e início dos anos 90 do século pretérito, demarcando uma nova modalidade de enfrentamento do latifúndio, da violência e dos conflitos pela posse da terra.

O Assentamento está localizado aproximadamente a $20 \mathrm{~km}$ da cidade de Parauapebas, no sudeste paraense. A então fazenda Rio Branco foi ocupada pelos semterra em 1994 e só foi oficializada pelo Instituto de Nacional de Colonização e Reforma Agrária (INCRA) em 1995. Possui uma área de 14.922 hectares, onde há 517 famílias assentadas (MICHELOTTI, 2008).

Dados de uma pesquisa do Setor de Saúde do MST e da Associação de Produção e Comercialização dos Trabalhadores e Trabalhadoras do Assentamento Palmares e Região - APROCPAR -, realizada em setembro de $2017^{2}$, dão conta de que existem em torno de 10 mil moradores na Agrovila do Assentamento e, em média, 4 mil assentados residindo nos lotes de 25 hectares de terra nas Vicinais do Limão, Três Voltas e do Rio Novo. O aumento da população no assentamento se acelerou no início dos anos 2000, com a intensificação das operações de exploração mineral (ferro) da empresa Vale do Rio Doce, que atraiu para a região milhares de famílias vindas do Maranhão e de municípios paraenses vizinhos, em busca de um emprego e de melhores condições vida. São homens e mulheres os quais possuem alguma relação com as famílias assentadas, geralmente de parentesco ou vizinhança.

O município de Parauapebas localiza-se na mesorregião Sudeste Paraense. Surgiu de um povoado do então município de Marabá, no curso do rio Parauapebas, no final dos anos 60 do século XX, em decorrência da descoberta da jazida de ferro e no contexto das políticas econômicas nacionais e globais que fomentaram e financiaram o processo de ocupação da região por meio das frentes de expansão (VELHO, 2009).

A região que hoje é o município de Parauapebas era um território habitado por povos indígenas Xikrins do Cateté, subdivisão dos Kaiapós, Castanheiros e Beradeiros, os quais viviam do extrativismo de produtos da floresta, cujas expressões mais simbólicas eram os imensos castanhais; a criação de pequenos animais; o cultivo de áreas de roçados de mandioca; a caça e a pesca.

$\mathrm{O}$ processo de ocupação do sudeste paraense foi protagonizado pelo governo militar sob a lógica desenvolvimentista a partir dos anos 70 do século XX e se consolida com a implantação do Programa Grande Carajás (PGC), que estimulou - entre outros eventos - a chegada de mais pessoas à procura de oportunidades econômicas, resultando no boom demográfico ocorrido em 1985, com mais de 500 mil pessoas amontoadas em aglomerações em Marabá e, posteriormente, nos municípios criados, como: Eldorado dos Carajás, Curionópolis, Parauapebas e Canaã dos Carajás. Esse cenário produziu

1 A colonialidade é um conceito diferente de Colonialismo, ainda que vinculado ao mesmo. A colonialidade é um dos elementos constitutivos e específico do padrão mundial do poder capitalista. Trata-se de uma categoria utilizada por Anibal Quijano (2010).

${ }^{2}$ Não existe um Censo Oficial realizado, seja pelo gestor público municipal ou pelo IBGE. 
concentração fundiária, grilagem de terras, conflitos, violência e injustiça ambiental na ocupação desigual do território por diversos atores sociais - migrantes sem-terra, posseiros, povos indígenas, colonos, fazendeiros, madeireiros, garimpeiros, entre outros (NAASE, 2010; VERDE, 2009; MOTTA, 2012).

Hoje, Parauapebas tem seu espaço distribuído e marcado por quatro frentes: a) área de mineração, sob o comando da Vale; b) área de preservação ambiental ou Verde, dividida entre a Terra Indígena dos Xicrins do Cateté e uma área de Conservação Ambiental, chamada de Cinturão Verde, gerenciada e regulada pela Vale; c) Um mosaico de Unidades de Conservação controlada pela Vale e d) área de mancha marrom sob o uso de pecuária e agricultura, de posse de fazendeiros e trabalhadores e trabalhadoras rurais dos assentamentos regulamentados pelo INCRA (BRINGEL, 2015). Esse processo de espacialização na fronteira amazônica é uma das evidências de que na mesma mesorregião coexistem diferentes interesses e, por isso, trata-se de um cenário de conflitos e violência, sob a égide do processo de acumulação capitalista.

\title{
2. Comunicação Alternativa, Dialogia e Não Violência
}

No Brasil, prevaleceu ao longo da história uma desigualdade no acesso à terra, produto direto do processo de colonização excludente, autoritário, patrimonialista e patriarcalista. Grandes extensões de terra (latifúndios) foram destinadas e/ou expropriadas, desde o período colonial, por grandes proprietários de monoculturas e fazendas, sendo símbolo de poder. Escravos, ex-escravos ou homens livres de classes subalternas $^{3}$ tiveram dificuldades de posse da terra. Em tempos de agronegócio e de expansão da fronteira agrícola para a Amazônia, a lógica colonial e colonizadora se alterou muito pouco.

O MST surge nesse contexto de luta pela distribuição mais justa da terra, no início dos anos 1980, em meio a um regime ditatorial, e se consolidou em território brasileiro como um dos mais importantes movimentos sociais do país, caracterizando-se como um movimento camponês popular que almeja a construção da Reforma Agrária para atender milhões de sem-terra. Seu lema é: "ocupar, produzir e resistir" e sua metodologia de organização se fundamenta no trabalho de base, que pressupõe reunir homens e mulheres que se encontram em situação de exclusão social, política, econômica e cultural (FERNANDES, 2000).

De acordo com Peruzzo (2007, p. 2):

\begin{abstract}
Movimentos populares são manifestações e organizações constituídas com objetivos explícitos de promover a conscientização, a organização e a ação de segmentos das classes subalternas visando satisfazer seus interesses e necessidades, como os de melhorar o nível de vida, através do acesso às condições de produção e de consumo de bens de uso coletivo e individual; promover o desenvolvimento educativo-cultural da pessoa; contribuir para a preservação ou recuperação do meio ambiente; assegurar a garantia de poder exercitar os direitos de participação política na sociedade e assim por diante. Em última instância, pretendem ampliar a conquista de direitos de cidadania, não somente para pessoas individualmente, mas para o conjunto de segmentos excluídos da população.
\end{abstract}

\footnotetext{
${ }^{3}$ Gramsci indica que o termo subalternidade, mais do que ter um significado fixo e isolado, reflete na realidade uma "relação", ou seja, se existe a subalternidade, existe, pois, a dominação de um grupo/classe sobre o outro. Classes ou grupos subalternos, como afirma Gramsci, o são em relação a outras classes dominantes. Os indivíduos pertencentes aos grupos subalternos possuem diferentes etnias, culturas e religião. São grupos que historicamente não apresentam uma homogeneidade no âmbito políticoinstitucional, o que os torna susceptíveis a sofrer influências das classes dominantes (SILVA, 2016).
} 
Nesta perspectiva, os movimentos populares atuam no meio social no sentido de possibilitarem a integração de setores excluídos da sociedade, seja no campo ou na cidade. As estratégias das organizações variam de acordo com o campo de atuação e da área social que atuam. No entanto, cabe ressaltar que os movimentos populares têm como perspectiva de atuação a não violência, a justiça social, a garantia de direitos e a mudança das estruturas que produzem a miséria e a exclusão.

O processo de organização, luta e resistência de sujeitos sociais pressupõe estratégias de comunicação. A comunicação está no cerne da organização do MST. Sua compreensão da comunicação parte de reflexões freirianas fundadas na dialogia e na autonomia dos interlocutores no processo comunicacional. Eles elaboram a crítica aos meios de comunicação de massa, que, por vezes, potencializam a subalternidade, e, assim, enfatizam o papel libertador e transformador da comunicação. Nesse sentido, assumem as reflexões de Paulo Freire: a "Comunicação é a coparticipação dos Sujeitos no ato de conhecer [...] ela implica numa reciprocidade que não pode ser rompida [...] comunicação é diálogo na medida em que não é transferência de saber, mas um encontro de sujeitos interlocutores que buscam a significação dos significados" (1971, p. 66-69).

No caminho dessa lógica da comunicação como autonomia e independência nas ações dos sujeitos do campo, a reflexão filosófica da resolução de conflitos pela não violência, proposta pelo filósofo Jean-Marie Muller, em "O princípio da não-violência; uma trajetória filosófica" (2007), esclarece a importância da atitude dos indivíduos em relação aos pressupostos incoerentes e injustos. Portanto, somado a Freire, Muller provoca, ao desenvolver a reflexão sobre a não cooperação; para o autor, são os próprios membros das sociedades históricas, como oprimidos, a parcela responsável por fornecer mecanismos de opressão aos tiranos (MULLER, 2007, p. 85). Ele explica que a não cooperação é uma proposição essencialmente estratégica do princípio da não violência; o indivíduo, ou grupo, ou sociedades, rebelam-se à desordem estabelecida, que se fundamenta na cumplicidade entre seus pares. Portanto, a não cooperação é uma luta declarada à cumplicidade das ideologias, estruturas, instituições, leis as quais mantêm as injustiças.

Muller lembra da greve geral, como ilustração de modelo da não cooperação; cidadãos estão dispostos a destituir injustiças as quais ameaçam seu poder de ação e de destino. Outro dispositivo é a desobediência à lei, quando esta apresenta-se em sua disfunção. "Aqueles que se submetem a uma lei injusta são responsáveis por essa injustiça, pois o que constitui a injustiça não é a lei injusta, mas a obediência à lei injusta" (MULLER, 2007, p. 88-89).

A proposta de reivindicar via desobediência à lei, para os cidadãos, é uma afirmação de poder político; parar de ser oprimido e não abrir mão dos seus direitos, ser ativo. Muller (2007, p. 89-94) apresenta mais duas outras propostas de sustento da ação não violenta, que historicamente colaboraram para sua formação: a "tomada da palavra para dizer a verdade" e a "força do humor".

A "tomada da palavra" é sinônimo de tomada de poder. Contudo, o autor alerta para que a linguagem utilizada não seja da mesma ordem da linguagem que contesta. "A pacificação da palavra é uma das exigências da não violência” (MULLER, 2007, p. 90).

Nesse sentido, a tomada da palavra, do direito à informação pela Rádio Comunitária/Alternativa Palmares, tem sido o eixo principal de resistência e performance de exploração de suas narrativas, pautando a história do Movimento e da comunidade pela via dos seus próprios protagonismos e de sua atuação autônoma. 
O outro indicativo de Muller (2007, p. 93), a força do humor é suportar tanta adversidade e, ao mesmo tempo, não perder a força de permanecer bem-humorado. É um método de resistência, portanto. "[...] O humor não é resignado e sim desafiador", além de "[...] oferecer a possibilidade de se proteger contra o ódio e a violência" (MULLER, 2007, p. 94).

Para aprofundar essa trajetória, Muller (2007, p. 18-28) descreve o conflito, a agressividade, a luta, a força e a coerção como conceitos comumente pouco entendidos, em razão da compreensão polarizada da violência e da não violência.

Ao tratar de "conflito", ele propõe que a existência humana predispõe a relação com o outro. Mas o caráter dessa relação geralmente é controverso, encarado como enfrentamento, pois o outro tende a causar inquietação, estranheza, medo. "Meu medo do outro se intensifica quando ele não é igual a mim, quando não fala a mesma língua, não tem a mesma cor, exibe uma fé num Deus que não é o meu" (MULLER, 2007, p. 18). E, geralmente, o que está ocupando maior valor nesse conflito, é o desafio do poder.

No caminho conceitual sobre conflito, Muller esclarece que há conflitos destruidores e conflitos construtivos, e aposta neste último como função estruturante da relação dos indivíduos. Nesse sentido, completa que pelo conflito se estabelece a possibilidade de um contrato entre as partes, com o objetivo de gerar equidade entre elas, de uma forma que garanta seus respectivos direitos. E alerta que, quando uma pessoa foge à situação conflituosa, está automaticamente abdicando dos seus direitos por isso a necessidade de ser ativo frente à adversidade do outro, mesmo diferente e distante (MULLER, 2007, p. 20).

Provocar; a paz "[...] não é, não pode ser e nunca será a ausência de conflitos, mas sim o controle, a gestão e a resolução dos conflitos por outros meios que não os da violência destruidora e mortal. A ação política também deve visar a resolução (do latim resolutio, 'a ação de desatar') não violenta dos conflitos" (MULLER, 2007, p. 20).

Portanto, pontua-se o conflito como manifestação primária no relacionamento humano, justificando-o como proposta de superá-lo. O esforço humano deve concentrarse na troca pacífica com o outro, e sua conduta deve ser liberada de quaisquer vestígios de ameaça e de medo.

A criação da Rádio Palmares e sua história de 25 anos propõem, em resposta às representações simplistas e parcializadas negativamente sobre o MST, como atitude necessária a não violência ao conflito posto entre os interesses da maior parte da mídia tradicional. O fato de, na narrativa da Rádio, os membros da comunidade se autorrepresentarem como sujeitos ativos e atuantes nessa esfera de diversidade de ideologias, corrobora o desafio permanente de buscarem seu pertencimento a suas filosofias e raízes culturais.

$\mathrm{Na}$ abordagem do conceito de "agressividade", Muller (2007, p. 21), indica a violência como uma de suas formas de expressão. De forma positiva, o ser humano tem a tarefa de mobilizar-se numa situação injusta e violenta, mas, por meio da agressividade, ele realiza o movimento de não se resignar e preferir a revolta, despertando para a luta, o conflito. Ou seja, para Muller a agressividade é necessária para levantá-lo da inércia e da passividade. "O conflito só ocorre a partir do momento em que o escravo demonstra agressividade suficiente para 'ir ao encontro' (ad-gradi) de seu senhor, ousar enfrentá-lo e reivindicar seus direitos". Dessa forma, a violência é a "perversão" da agressividade (MULLER, 2007, p. 23).

No tópico seguinte, "a luta", o filósofo recupera que quando não há equidade entre as partes, ou seja, um embate injusto, o diálogo não ganha forças de ser desenvolvido, e, para isso, a função da luta defendida por Muller é tender a "[...] criar as 
condições de diálogo, estabelecendo uma nova relação de força que obrigue o outro a me reconhecer como um inter-locutor necessário" (MULLER, 2007, p. 24).

No que diz respeito a "força", Muller explica: qualquer luta é uma evidência de força. Ele desenvolve a teoria sobre força, recorrendo à ideia sobre a justiça se conceituar como um equilíbrio entre forças antagônicas e, para haver esse equilíbrio e simetria entre as forças, exerce-se uma outra força que deva impor limites à força a qual desempenhou o desequilíbrio inicial. Para tratar da força que estabelecerá esse limite, é importante considerar a noção de "bela ação" de Simone Weil (apud MULLER, 2007, p. 25): “[...] a 'bela ação' é 'a ação que interrompe, que suspende o diálogo indefinido dos desequilíbrios que se rebatem, estabelecendo o equilíbrio único correspondente àquela situação específica'. A ação não violenta quer ser essa 'bela ação', que visa estabelecer o equilíbrio das forças para assegurar a justiça e a paz". A prática da força é a ação (a "bela ação") e, pelo movimento aproximado da justiça, pode constituir a união. Isso se dá porque, para Muller (2007, p. 27), aqueles que sofrem a injustiça, tendem a se unir para uma ação conjunta, objetivando lutar pelas conquistas da justiça.

O último conceito mal-interpretado pelas sociedades, para Muller (2007, p. 27), é o uso do processo coercitivo. "Coagir alguém significa obrigá-lo a agir contra sua vontade: há pouco, ele não queria, mas agora já aceita".

O autor justifica a recuperação da ação coercitiva no caminho filosófico da não violência pelo entendimento de os conflitos atuais serem muito mais próximos de emblemáticos combates, de forças e de poder. Para ele, essas forças são representadas por grupos de pessoas com interesses específicos, os quais estão alinhados à justificação racional da ideologia da violência. "Por isso, quando se trata de lutar contra as injustiças estruturais da 'desordem estabelecida', a pressão exercida pela ação coletiva é determinante para o sucesso de uma resistência não violenta" (MULLER, 2007, p. 28). Ou seja, neste processo, forçar o outro a encontrar mudanças nas escolhas, a realizar concessões e, inclusive, a ceder na racionalização, tem como objetivo a negociação, em prol de uma solução mais justa entre os grupos.

Enquanto essa negociação requer as forças em jogo de forma equitativas, o estudo da narrativa da Rádio Palmares problematiza a necessidade de ir ao conflito via direito à informação e dar voz aos sujeitos atuantes, além de colaborar na dialogia das relações afetivas da comunidade e nas afirmações de identidades presentes no local do Assentamento.

É por isso que o entendimento ampliado das terminologias políticas e históricas sobre conflito, agressividade, luta, força e coerção remete ao cidadão ativo e à potencialidade da sabedoria racional acerca da filosofia da não violência como uma alternativa pacífica, mas resistente e desafiadora. De acordo então com a proposta filosófica de Muller (2007), optar pela não violência é uma recusa de fazer da violência algo justo e, ao mesmo tempo, fazer do que realmente é justo algo forte (PASCAL apud MULLER, 2007, p. 96).

\section{Metodologia}

O presente trabalho se estrutura a partir de diálogos com lideranças ligadas ao MST no Pará, que manifestaram interesse de continuar produzindo reflexões sobre o processo de organização e luta camponesa na Amazônia, especialmente a partir da história de 25 anos de luta e resistências no Assentamento Palmares II.

Em função das mudanças ocorridas nos últimos dez anos, com o aumento da população na Agrovila do Assentamento e de jovens desempregados, surgiu a proposta de fazer uma reflexão teórico-metodológica sobre o papel da comunicação 
comunitária/alternativa/popular nesse novo contexto de urbanização, aproximação da juventude (que não está tão motivada com a vida no campo) e expansão da mineração da Vale, inclusive aumentando os serviços e a infraestrutura dentro do assentamento.

O ponto inicial foi a sistematização das experiências da Rádio Comunitária Palmares, a partir da leitura de relatórios, da realização de entrevistas com dirigentes do MST, de diálogos junto aos assentados, roda de conversas e da participação no congresso que discutiu os 25 anos de avanços e desafios da Palmares, com o intuito em compreender a trajetória da comunicação a partir das narrativas da Rádio.

Nesse sentido, utilizamos a metodologia qualitativa, de natureza colaborativa não extrativista apresentada por Boaventura de Sousa Santos (apud FAZANELLO; NUNES; PORTO, 2018, p. 4).

Realizar trabalhados a partir dessa perspectiva teórico-metodológica pressupõe valorizar processos comunicacionais e diálogos em que as questões, respostas e explicações encontradas para um dado problema de pesquisa são construídas coletivamente, valorizando as contribuições e as informações descobertas no contexto construtivo e dinâmico.

A matriz metodológica qualitativa, colaborativa e não extrativista pressupõe a defesa de formas alternativas de produção de conhecimento, valorizando o protagonismo dos atores, sujeitos dos processos sociais. "Sua relação com a comunicação, entendida não apenas como um campo de conhecimentos e práticas, mas também como um componente irredutível dos possíveis encontros e diálogos entre pessoas e grupos sociais com seus saberes, culturas e lutas por dignidade" (FAZANELLO; NUNES; PORTO, 2018, p. 4).

Conforme assinala Becker (1994), é fundamental a compreensão sociológica da relação entre pesquisadores e sujeitos potenciais de estudo, de modo a possibilitar a elaboração de métodos analiticamente apropriados para garantir acesso aos grupos em estudo, na perspectiva de intercambiar conhecimentos.

O presente artigo se amparou dessa proposta, buscando, durante a investigação, a construção de evidências, valorizando a colaboração dos sujeitos sociais históricos, não apenas como simples informantes, mas como partes inerentes do processo da pesquisa. Para tanto, a coleta, organização e interpretação das informações levantadas tiveram a natureza qualitativa, pois partimos do pressuposto de que lócus do objeto de estudo se constrói em círculo, envolvendo história e cultura, presente e passado, em um processo dialético (totalidade, movimento e contradição) permanente.

Como o artigo trata sobre comunicação e populações camponesas assentadas, sujeitos de transformação social, foi necessário que a pesquisa estivesse atenta e comprometida sem, no entanto, deixar de questionar, refletir e revelar novos significados, problematizando o território.

De acordo com Martins, uma revisão histórica das lutas do campesinato na Amazônia demonstra que "os camponeses representam uma resistência àquilo que $o$ racional (e capitalista) tinha e tem de desumanizador. Elas proclamam aquilo que o capitalismo não fez e nem podia fazer. Desenvolver uma concepção do humano e do homem" (MARTINS, 1992, p. 29-30). Essas evidências foram percebidas nas narrativas da Rádio Palmares por meio da trilha colaborativa não extrativista, de natureza qualitativa, e de um trabalho artesanal e cuidadoso.

\section{Resultados e Discussão}


A partir dos anos de 1990, com a chegada do MST no Pará, a luta pela terra ganha novos contornos políticos na Amazônia. A luta e a resistência dos posseiros, ligados ao Sindicato dos Trabalhadores Rurais - STRs, descritos por Pereira (2013), Michelloti (2008) e Morena e Guerra (2012), entre outros estudiosos, analisam que a práxis de enfrentamento do latifúndio, da violência e dos conflitos era marcada pela ação coletiva de posseiros que ocupavam terras devolutas e latifúndios improdutivos. Com o MST, dois elementos novos ecoam na metodologia organizativa e na ação coletiva de luta e resistência.

As lideranças ligadas ao STRs, geralmente, eram homens e viviam em vilas e cidades, distantes do seu grupo social (camponeses acampados e assentados) o que facilitava a ação violenta da pistolagem. $\mathrm{O}$ apoio da igreja católica foi fundamental ao longo da história de luta de pela terra. As Comunidades Eclesiais de Base (Cebs) e suas pastorais sociais, como a Comissão Pastoral da Terra (CPT), tiveram um papel fundamental na defesa dos direitos humanos e na denúncia das diversas formas de violência. A Central Única dos Trabalhadores (CUT) teve papel estratégico na organização dos trabalhadores em sindicatos, o que fortaleceu a luta dos posseiros.

No MST, as lideranças são homens e mulheres que vivem nos assentamentos, pois após a ocupação da terra organizam coletivos (saúde, cultura, segurança, educação, produção, entre outros) e aguardam a desapropriação em áreas coletivas. O núcleo de apoio se expande para além da igreja católica e da CUT, incluído não só outras igrejas evangélicas, mas também movimentos populares e urbanos locais e regionais.

Outro elemento importante que se fortalece com a ação do MST é a dimensão política da luta pela Reforma Agrária. Ampliam-se as redes de relações e articulações locais, regionais, estaduais, nacionais e internacionais. No bojo desse processo emerge a necessidade da ação midiática, como ferramenta de disputa democrática da opinião pública e da difusão do ideário do Movimento, bem como sua importância, tanto para o campo, como para a cidade. Com isso, percebemos que desde o surgimento do MST, a comunicação se coloca como parte fundamental da estratégia para conquista da terra e ampliação dos laços de solidariedades e redes de apoio.

Nessa perspectiva, a Agrovila de um assentamento também abarca núcleos essenciais de Educação, Saúde, Produção, Cultura e Comunicação, em que se busca participação da localidade em um processo social coletivo, dentro da área de ocupação. Isso favorece a luta e organização de homens, mulheres, crianças e jovens, tornando-se espaço fundamental para possibilitar os diálogos e favorecer as interações sociais. $\mathrm{O}$ espaço público do assentamento, tais como Postos de Saúde, Escolas, Sedes das Associações e Cooperativas consolidam-se como lugar de luta e resistência, de sociabilidade, de troca de saberes, do exercício do cuidado, de partilha e de ampliação das redes de relacionamentos autônomos.

A comunicação para o MST, portanto, é algo essencial para a luta e resistência na terra, na perspectiva de criar e estimular laços de unidade e solidariedade. Desta forma, a Rádio Comunitária ${ }^{4}$ surge nesse contexto de mobilização e acampamento de quatro mil pessoas, em Parauapebas, que se deslocam para o INCRA de Marabá para reivindicarem a posse da terra. Inicialmente, conforme descreve a Coordenação de Comunicação da APROCPAR, a Rádio Comunitária possibilitava o intercâmbio de informações e a organização da vida comunitária.

\footnotetext{
${ }^{4}$ Mesmo depois de 25 anos de implantação, a Rádio Palmares ainda não foi regulamentada pelas dificuldades institucionais e burocráticas (políticas), o que tem imposto dificuldades no seu funcionamento, mas não a impedindo de atuar.
} 
Foi desde o acampamento do INCRA, em Marabá, que a coordenação instituiu um veículo de comunicação de massa, composto por um amplificador, uma "boca de ferro", um microfone e um toca-fitas velho que, instalados num barraco, passavam informações do dia a dia do acampamento: assembleias, reuniões dos grupos de família, dos setores, realizando tarefas de utilidade pública do acampamento. Durante a permanência do acampamento da cidade, além de tocar músicas do movimento, e das atividades que orientavam a organização da vida comunitária, vai se criando uma programação, que incorpora horário de informativo dos setores e programa religioso. (APROCPAR, 2017)

De volta à Parauapebas, a Rádio Comunitária foi montada dentro da ocupação, na então Fazenda Rio Branco, e continuou sendo um espaço de difusão de informações e debate público sobre o conteúdo ligado a luta e resistência, que se expressa na mobilização para definição do nome do assentamento. A rádio estimulou o debate no sentido de apresentar propostas diversas para escolher o nome que representasse a história e a luta dos camponeses. Por se tratar de um assentamento constituído com maioria de negros, ex-garimpeiros, ex-lavradores migrantes da fronteira amazônica, vindos essencialmente do Maranhão e Piaú, "Palmares" vai se aproximando da expressão que garante identificação com àquele território. Relatórios da APROCPAR e entrevistas com os Coordenadores de Comunicação do Movimento indicam essa expressão:

Durante o processo de resistência durante a ocupação, a rádio vai ter papel de relevante importância. Ela, através da "voz" (que ficava na ponta de um pau fincado no centro do acampamento) unificava as informações repassadas ao acampamento. Já havia um coletivo responsável por tocar a programação da rádio, incluindo o uso de uma máquina de datilografar para a redação de algumas informações. Nesse processo está o próprio processo de escolha do nome do assentamento, cujo processo saí no dia 5 de novembro de 1995: Assentamento Palmares, nome em homenagem à Resistência de Quilombo dos Palmares, que naquela data fazia aniversário de 300 anos. (APROCPAR, 2017)

Com a consolidação do Assentamento e a constituição da Agrovila, a Rádio Comunitária amplia ainda mais sua importância no processo de comunicação com a Agrovila e os assentados que residiam nas vicinais distantes do núcleo urbano, além da área rural do Contestado, de Marabá e Curionópolis. A coordenação da APROCPAR esclarece as assimetrias postas durante o processo de crescimento da Rádio e seu papel na luta contra a acumulação do capital global, representado pela atuação e expropriação mineral realizada pela Vale. Relatos e entrevistas com lideranças do MST dão conta desse processo.

Durante nossa história da vila, a rádio passa por vários estágios. Passa por um período longo como "rádio de boca de ferro" que estende até 2000, até a Rádio FM em 2001, funcionando já num prédio próprio e com um coletivo mais "profissional". Entre altos e baixos ela retoma com uma potência maior em 2007, agora com um estúdio, com equipamentos mais modernos e também com uma programação de 24 horas ininterruptas. Ela vai ter papel importantíssima na coordenação das ações de comunicação, informação e propaganda durante a Jornada de Lutas contra a mineração em setembro de 2007, que culmina com a primeira grande ocupação dos trilhos da Estrada de Ferro Carajás, principal via da logística de transporte de minério da já privatizada CVRD, que após, adota o nome de Companhia Vale. Em 2009 ela sofre interferência da Polícia Federal: equipamentos são presos e confiscados e militantes são processados. A rádio é fechada. Por um longo período ela 
aparece e desaparece no ar, com períodos curtos de programação e sem local fixo. (APROCPAR, 2017)

A partir de 2015, a Rádio Comunitária Palmares II começa a se restabelecer, mas somente em 2016 se instala nas dependências da APROCPAR, que dá a ela uma retaguarda jurídica. A Rádio agora é um instrumento de comunicação e utilidade pública, que conta com um coletivo de comunicação que discute linhas gerais da programação, e é coordenada por lideranças do MST, em permanente diálogo com a comunidade.

Em entrevistas com trabalhadores e trabalhadoras assentadas, localizados nas vicinais do Limão e de Três Voltas, confirmou-se a assertiva da Coordenação de Comunicação, de que a Rádio Palmares FM, 106,3, mesmo considerando a concorrência com outras rádios comerciais da região, continua cumprindo um papel de difusão de informações e de conteúdo de interesse coletivo, que fortalece a unidade e os laços de solidariedade no assentamento. Nessa linha, os Coordenadores assim declaram:

A Rádio Palmares FM, 106,3 - é a principal ferramenta de comunicação da associação com os(as) trabalhadores(as) rurais, em especial aqueles que moram fora da vila, nas parcelas rurais, onde o acesso a internet é quase inexistente. Sua potência atinge todos os 15 mil hectares do assentamento Palmares, mais toda sua vizinhança rural, tem alcance na periferia da cidade de Parauapebas, Curionópolis e zona rural da área do contestado (Marabá). (APROCPAR, 2017)

Conforme declararam os assentados, a programação vincula-se aos modos da vida no campo e da realidade de hibridismo cultural que caracteriza as famílias que integram o assentamento Palmares II. Os conteúdos estão relacionados ao processo de luta e resistência dos trabalhadores e trabalhadoras rurais e à importância do MST como movimento que organiza ações coletivas no meio rural. Aborda-se, por meio de entrevistas e notícias locais e nacionais, a reforma agrária, os projetos e programas da agricultura familiar, as atividades das Associações e Cooperativas e as questões sociais no Assentamento, como a educação, saúde, produção e comercialização. Há também noticiários nacionais e estaduais sobre a organização camponesa e a realidade do Pará e do Brasil no que tange a vida política, econômica, social e agrária. As músicas são geralmente modão sertanejo e cantos que refletem a história e luta camponesa.

Os relatórios e as entrevistas com os Coordenadores de Comunicação da APROCPAR indicaram que a continuidade da atuação da Rádio Comunitária Palmares depende de novos investimentos de modernização e infraestrutura. Mas o desafio que mais inquieta as lideranças do Movimento é o de oferecer um conteúdo/programação inovador e comprometido com a ação camponesa, que atinja e encante os jovens desempregados e desiludidos com a vida no campo pelas dificuldades e desafios que se impõem. De acordo com a Coordenação de Comunicação da APROCPAR, torna-se urgente ainda estabelecer-se na web e conectar-se com outras plataformas e redes sociais de comunicação. "Isso exige qualificação de multiplicação de pessoal (capacitação, treinamento, formação específica, formação política), gestão e planejamento de curto, médio e longo prazo", concluem as lideranças do MST.

\section{Considerações Finais}


A comunicação comunitária/alternativa/popular é um instrumento fundamental nas lutas sociais e populares, no campo e na cidade. Mesmo que não seja uma força dominante, desempenha um papel no processo de democratização da informação, promovendo conteúdos ligados às discussões sobre cidadania, gênero, justiça social, direitos humanos, sustentabilidade, reforma agrária, economia solidária, entre outros.

A Rádio Palmares FM, ao longo de 25 anos de história, cumpriu esse papel como parte da estratégia do MST no processo de ocupação e resistência na terra. As informações registradas no presente artigo explicam a dificuldade em manter esse instrumento de comunicação. Entre os desafios enfrentados estão a carência de pessoal capacitado no campo da comunicação e a sua atualização técnica e de infraestrutura.

A luta pela narrativa histórica da rádio, mesmo que não legalizada, foi compreendida, pelos autores deste artigo, como não cooperação (MULLER, 2007) com as imposições midiáticas a respeito das representações do MST pelos veículos tradicionais. Nesse sentido, as comunidades camponesas que não se veem nesses processos de estereotipagem trouxeram a realidade da rádio comunitária/alternativa como resistência e plataforma de comunicação interna, para seu fortalecimento. É por isso que os integrantes da rádio Palmares resistiram e resistem de forma não violenta, rompendo a cumplicidade das normatizações de comunicação, por meio da organização de ações coletivas de não cooperação, como são as narrativas de inclusão dos sujeitos atuantes da comunidade (MULLER, 2007, p. 85).

No entanto, o que se tem colocado em questão para a continuidade da Rádio Palmares são também as novas modalidades de mídias sociais (Facebook e WhatsApp) que tomam conta do assentamento e atraem, principalmente, os mais jovens, que são os menos interessados em continuar vivendo no assentamento. Soma-se a isso a publicização de que um emprego na mineração da Vale representa uma mudança imediata na vida dos jovens camponeses.

As entrevistas mostraram que o público que escuta a Rádio diminuiu com o tempo, apesar da Coordenação não dispor de uma pesquisa sobre essa temática. $O$ importante a destacar é que, frente a esses novos desafios, a APROCPAR tem procurado estabelecer parceria com a Universidade Federal do Sul e Sudeste do Pará UNIFESSPA - para qualificação de novos comunicadores, atualização de formato e dinâmica das programações, bem como para a aquisição de equipamentos e softwares que fazem a conexão da Rádio à Web. São desafios atuais para uma rádio alternativa e comunitária em uma região pautada por conflitos e imposições empresariais e esses são temas de pesquisa para próximos artigos. 


\section{Referências bibliográficas}

APROCPAR (Associação ligada ao MST). Relatório sobre a Rádio Palmares, Parauapebas, Assentamento Palmares. Mimeo. 2017

BARBOSA, Alexandre. A comunicação do MST: uma ação política contrahegemônica. Tese (Doutorado em Interfaces Sociais da Comunicação) - Escola de Comunicações e Artes, Universidade de São Paulo, São Paulo, 2013. Disponível em: https://www.teses.usp.br/teses/disponiveis/27/27154/tde-26022014-

120204/publico/ALEXANDREBARBOSACorrigida.pdf. Acesso em: 15 mar. 2019.

BECKEC, S. Howard. Método de Pesquisa em Ciências Sociais. Trad. Marcos

Estevão e Renato Aguiar. São Paulo: Hucitec, 1999.

BRIGEL, Fabiano de Oliveira. Fronteiras Agrárias Intermitentes e processo de territorialização do campesinato na Amazônia: uma análise comparativa de projetos de assentamentos no sudeste e sudoeste do Pará. Tese de doutorado. UFPE. 2015, . Disponível em: https://repositorio.ufpe.br/handle/123456789/16974. Acesso em: 16 mar. 2019.

FAZANELLO, Marina Tarnowski; NUNES, João Arriscado; PORTO, Marcelo Firpo de Souza. Metodologias colaborativas não extrativistas e comunicação: articulando criativamente saberes e sentidos para a emancipação social. Revista Eletrônica de Comunicação \& Inovação e Saúde. Rio de Janeiro, v. 12, n. 4, 2018. Disponível em:

https://www.reciis.icict.fiocruz.br/index.php/reciis/article/.../1527. Acesso em: 15 mar. 2019.

FERNANDES, Bernardo Mançano. A Formação do MST no Brasil. Rio de Janeiro. Vozes, 2000.

FREIRE, Paulo. Pedagogia da autonomia. Saberes necessários à prática educativa. 48 . ed. Rio de Janeiro: Paz \& Terra, 2014.

Extensão ou comunicação? Rio de Janeiro:. Paz e Terra, 1971.

HABERMAS, J. The theory of communicative action. v. 1. Reason and the rationalization of society. Boston: Beacon Press, 1984.

LIMA, Vinicius A. de. Comunicação e Cultura: as ideias de Paulo Freire. Brasília: Editora da UNB e Fundação Perseu Abramo, 2015.

MARTINS, José de Souza. Educação e cultura nas lutas do campo (reflexão sobre uma pedagogia do conflito). In: ALBA, Maria Zaluar et al. Sociedade Civil e Educação. São Paulo: Papirus, Cedes, 1992. 
MICHEOTTI, Fernando. Luta pela Terra e Assentamentos no Sudeste do Pará. Trabalho apresentado no $3^{\circ}$ Encontro da Rede de Estudos Rurais, realizado entre os dias 9 e 12 de setembro, Campina Grande, Paraíba, 2008.

MORENO, Glaucia de Sousa; GUERRA, Gutemberg Armando Diniz. O drama da instalação de famílias agricultoras na mesorregião sudeste paraense. Revista NERA. Presidente Prudente, ano 15, n. 21, p. 79-99, jul.-dez. 2012.

MOTTA, Edilson. A população indígena de Parauapebas. Disponível em: https://www.slideshare.net/adilsonmottam/populao-indgena-de-parauapebas. Acesso em: 15 mar. 2019.

MULLER, Jean-Marie. O princípio da não-violência. Uma trajetória filosófica. Trad. Inês Polegato. São Paulo: Palas Athena, 2007.

NAASE, Karin Marita. Recursos naturais, espaço social e estratégias de vida em assentamentos da reforma agrária na Amazônia brasileira (Sudeste Paraense). Boletim do Museu Paraense Emílio Goeldi. Ciências Humanas. Belém, v. 5, n. 1., jan.-abr. 2010.

PEREIRA, Airton dos Reis. Do Posseiro ao Sem Terra: a Luta pela Terra no Sudeste do Pará. Recife: Editora da UFPE, 2015.

PERUZZO, Cicilia M.K. Comunicação nos movimentos populares: a participação na construção da cidadania. 4. ed. Petrópolis: Vozes, 2004.

Direito à Comunicação Comunitária, Participação Popular e Cidadania.

Revista do Programa de Pós-graduação em Comunicação Universidade Federal de Juiz de Fora. v. 1, n. 1., jun. 2007. Disponível em: http://www.ppgcomufjf.bemvindo.net/lumina. Acesso em: 15 mar. 2019.

Comunicação nos movimentos sociais: o exercício de uma nova perspectiva de direitos humanos. Revista Contemporânea, comunicação e cultura. Bahia:

UFBA/POSCOM, v. 11, n. 1, p. 138-158, 2013. Disponível em: http://www.portalseer.ufba.br/index.php/contemporaneaposcom/article/view/6980.

Acesso em: 15 mar. 2019.

Movimentos sociais, cidadania e o direito à comunicação comunitária nas

políticas públicas. Revista Fronteiras. São Leopoldo: UNISINOS, v. 11, n. 1, p. 33-43, 2009. Disponível em: http://revistas.unisinos.br/index.php/fronteiras/article/view/5039. Acesso em: 15 mar. 2019.

QUIJANO, Anibal. Colonialidade do poder e classificação social. In: SANTOS, Boaventura de Sousa; MENEZES, Maria Paula. Epistemologias do Sul. São Paulo: Cortez, 2010.

SENNETT, Richard. Juntos. Os rituais, os prazeres e a política da cooperação. Rio de Janeiro: Record, 2012. 
SILVA, Salyanna de Souza. Contribuições acerca do tema classes subalternas em Gramsci. In: Jornada Internacional de Estudos e Pesquisas em Antonio Gramsci e VII Jornada Regional de Estudos e Pesquisas em Antonio Gramsci Práxis, Formação Humana e a Luta por uma Nova Hegemonia, 2016, Fortaleza. Anais... Fortaleza: Editora Jornada, 2016.

VELHO, Otávio. Frentes de expansão e estrutura agrária: estudo do processo de penetração numa área da Transamazônica. Rio de Janeiro: Centro Edelstein de Pesquisas Sociais, 2009.

VERDE, Rodrigo Braga da Rocha Villa; FERNANDES, Francisco Rego Chaves. Panorama sócio-espacial de Parauapebas (PA) após a implantação da Mina de Ferro Carajás. Disponível em:

http://verbetes.cetem.gov.br/verbetes/ExibeVerbete.aspx?verid=79. Acesso em: 15 mar. 2019. 